\title{
Bioactivity Guided Antidiabetic Formulation Development of Tridax procumbens Linn Leaves
}

\author{
Pranali Vijay Bansode ${ }^{1}$, Kiran Shivaji Patil ${ }^{2}$, Ashok Ananda Hajare ${ }^{1 *}$ \\ ${ }^{1}$ Department of Pharmaceutics, Bharati Vidyapeeth College of Pharmacy, Kolhapur, Maharashtra, INDIA. \\ 2Department of Pharmaceutical Quality Assurance, Tatyasaheb Kore College of Pharmacy, Warananagar, Maharashtra, INDIA.
}

\begin{abstract}
Purpose: Diabetes mellitus is a global health problem as it is one of the complex disease and main causes of premature illness and death. The present study was focused to scientifically overcome bioavailability drawbacks of Tridax procumbens Linn. and improve its medicinal use of for the treatment diabetes by formulating it into microemulsion from. In this study oil in water microemulsion of Tridax procumbens Linn leaves extract was prepared using olive oil, Tween 80 and propylene glycol for oral delivery. Methods: Phytochemical screening of Tridax procumbens Linn. leaves extract was carried out to isolate flavonoids by column chromatography. The o/w microemulsion of whole extract was prepared by water titration method followed by its evaluation for various physical tests and thermodynamic stability. The optimized formulation was tested for drug release in vitro and antidiabetic activity by in vivo study. Results: Tridax procumbens Linn. leaves extract isolated for the active moiety showed antidiabetic action in rats. The optimized Tridax procumbens Linn. extract microemulsion showed an average particle size $292.4 \mathrm{~nm}$. There was approximately 1.4 fold increase in drug release from microemulsion compared to marketed tablet formulation. At the end of seven days after oral administration of microemulsion a significant reduction in blood glucose level was observed. Conclusion: The optimized microemulsion was thermodynamically stable. The enhanced bioavailability of flavonoids in microemulsion proves the traditional claim with regard to Tridax procumbens Linn. for its antidiabetic activity.

Key words: Tridax procumbens, Microemulsion, Alloxan-induced diabetes, Hypoglycemic activity, Bioavailability.
\end{abstract}

\section{INTRODUCTION}

Diabetes mellitus is the world's third-largest, chronic, non-infectious disease affecting 425 million people globally and this figure is projected to increase up to 629 million by 2045 as per the report published by International Diabetes Federation. ${ }^{1}$ Diabetes is one of the complex disease and main causes of premature illness and death. Screening, diagnostic and therapeutic efficacy that favorably affect health outcomes along with cost-effective treatment for diabetes patient is the major focus area for the researchers. ${ }^{2}$

A wild plant named Tridax procumbens Linn. commonly known as "Ghamra" and in English "coat butt" belongs to family Asteraceae observed throughout India. ${ }^{3}$ It has been used since many years as an indigenous medicine for a variety of ailments and traditionally plant leaves powder has been used since decades in treating diabetic patients in Mandesh Maharashtra and the tribal populations of Udaipur district in Rajasthan. ${ }^{4}$ It has been also reported as anticoagulant, antifungal, hair growth promoter and has insect repellent and wound healing activities in Indian traditional phytotherapy. ${ }^{5}$ It has been reported in literature that orally administered alcoholic extracts of Tridax procumbens Linn. leaves at $200 \mathrm{mg} / \mathrm{kg}$ dose produces a substantial decrease in blood glucose level in human over the period of 7 days. ${ }^{6}$ TPE contains quercetin as active principles which protects beta cells against
Submission Date: 17-07-2019; Revision Date: 19-03-2020; Accepted Date: 15-04-2020

DOI: 10.5530/ijper.54.3.121 Correspondence: Dr. Ashok Ananda Hajare Department of Pharmaceutics, Bharati Vidyapeeth College of Pharmacy, Kolhapur Maharashtra, INDIA.

Phone: +91 9823695030

E-mail: ashok.hajare@ bharatividyapeeth.edu

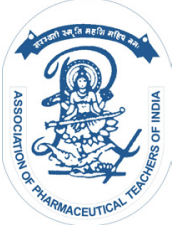

www.ijper.org 
damage by its anti-inflammatory, anti-apoptotic and antioxidant properties. It regenerates beta cells through stimulation of the ductal stem cell. Thus, quercetin been reported as an adjuvant drug in the management of diabetic mellitus. ${ }^{7}$ The poor solubility of quercetin and crystalline form at body temperatures limit its bioaccessibility and its bioavailability which limit out its use for diabetes treatment. ${ }^{8}$

Natural form of the TPE can be delivered via novel drug delivery system which will be efficient and effective and will have few side effects as compare to synthetic drugs. The term "microemulsion" refers to a thermodynamically stable isotropically clear dispersion of two immiscible liquids, such as oil and water, stabilized by an interfacial film of surfactant molecules. ${ }^{9}$ Microemulsion offer several advantages as drug delivery systems as these are thermodynamically stable along with enhancement of solubility and the bioavailability of less soluble drugs. The oil component penetrate and hence swell the tail group region of the surfactant monolayer leads to solubilization of lipophilic drug and surfactants and co-surfactants lowers interfacial tension to aid dispersion processes and also provide a flexible film that can readily deform arround small droplets. Appropriate hydrophile-lipophile character will provide the correct curvature at the interfacial region for the desired microemulsion. ${ }^{10}$ The present study was focused to scientifically overcome bioavailability drawbacks of Tridax procumbens Linn. and improve its medicinal use for the treatment of diabetes by formulating it into microemulsion from.

\section{MATERIALS}

Tridax procumbens Linn. was collected at Kandalgaon Dist. Kolhapur India. Botanical identification was performed by Dr. Yadav, Department of Botany Shivaji University Kolhapur. Quercetin, alloxan monohydrate, polyethylene glycol 400, polysorbate 80 and olive oil were received as gift samples from Loba Chem Pvt. Ltd. (Mumbai, Maharashtra, India). The water was obtained from standard sources.

\section{Animals}

Wistar rats weighing 200-250g of both sex were used for the animal experiments and were maintained under standard laboratory conditions at $25 \pm 2 \% / 50 \pm 15 \% \mathrm{RH}$ and at normal photo period (12 hr dark/12 hr light). Commercial pellet diet [Chakan oil mill, Sangli, India] and water was provided ad libitum. ${ }^{11}$

\section{METHODS}

\section{Extraction procedure}

The leaves of Tridax procumbens Linn. were dried under shade and ground in an electrical grinder to a coarse powder. Powdered leaves $(2.5 \mathrm{~kg})$ were extracted for 24 hr with water: ethanol at 70:30 and dried under reduced pressure on rotary evaporator. ${ }^{12}$

\section{Preliminary phytochemical studies}

The ethanolic extract of Tridax procumbens Linn. leaves was screened by phytochemical test for the presence of flavonoids, alkaloids, phenols, saponins, triterpenoids, glycosides and tannins using modified methods. ${ }^{13}$

\section{Identification of Flavonoids}

TLC technique was used to determine the presence of flavonoids in the extract. Toluene, ethyl acetate, formic acid at 5:4:0.2 proportions were used respectively for identification of flavonoids. ${ }^{14}$ The extract was run on silica gel $60 \mathrm{~F}_{254}$ pre-coated plate with $0.2 \mathrm{~mm}$ thickness. Visualization was carried out in iodine chamber by dipping the plate in it, till the color of the spot appears. Retention factor $\left(\mathrm{R}_{f}\right)$ was calculated as migration distance of substance to the solvent front.

\section{Isolation of active flavonoid fraction}

Ethanolic extract, $10 \mathrm{~g}$, was subjected to column chromatography using100-200 mesh silica gel (Merck, India) and eluted with 5:4:0.2 solvent system consisting of solvents toluene, ethyl acetate, formic acid to obtain five fractions. Each fraction was isolated twice using TLC and UV spectroscopy, separately, to confirm the presence of active Fraction, Table 1. This process was repeated several times with bulk quantity of the samples until the expected amount of flavonoids have been obtained. ${ }^{14}$

\section{Pre-formulation studies}

\section{Solubility study}

In order to prepare microemulsion, extracted oil and surfactants were selected on the basis of solubility study using equilibration method. A known amount of the

\begin{tabular}{|c|c|}
\hline \multicolumn{2}{|c|}{ Table 1: $\mathbf{R}_{\mathbf{f}}$ value of extract. } \\
\hline Compound & $\mathbf{R}_{f}$ value \\
\hline Quercetin & 0.7 \\
\hline Fraction 1 & 0.34 \\
\hline Fraction 2 & 0.5 \\
\hline Fraction 3 & 0.66 \\
\hline Fraction 4 & 0.6 \\
\hline Fraction 5 & 0.5 \\
\hline
\end{tabular}


TPE was dissolved in each of the oils, surfactants and co-surfactants followed by vortexing in stoppered vials and finally shaking at $100 \mathrm{rpm}$ for $72 \mathrm{hr}$ on an orbital shaker at $25 \pm 1^{\circ}$. These mixtures were further centrifuged for $15 \mathrm{~min}$ at $3000 \mathrm{rpm}$. The supernatant was filtered through $0.45 \mu \mathrm{m}$ membrane filter. The dissolved drug was diluted within the linearity range and was measured spectrophotometrically using UV-spectrophotometer (Shimadzu UV-1700) at $254 \mathrm{~nm} .{ }^{15}$

\section{Drug-excipient compatibility studies}

FTIR analysis was used to study drug-excipient interaction by scanning samples in the range of $400-4000 \mathrm{~cm}^{-1}$. The surfactant, co-surfactant mixture, oil alone and in combination with extract was analyzed. A spectral comparison was done with FTIR of the pure drug to understood significant functional groups of the drug interacting with the excipients. ${ }^{16}$

\section{Optimization of microemulsion components}

A series of mixtures were prepared by changing the ratio of optimized oil, surfactant and co-surfactant. These mixtures were prepared and subjected to a simple water titration method. Surfactants and co-surfactants with ratios 1:1, 1:2, 1:3 were mixed together to get different mixtures and fixed volume of oil were added into these mixtures and subjected to gentle shaking and vortexing. The final mixture was titrated against the water with constant stirring using magnetic stirrer. The disappearance of turbidity in the solution was identified as the end point of the titration. Mixtures were kept at room temperature under observation for one day. Milky white and turbid mixtures get separated and specified as unstable emulsions thus termed as biphasic. The clear, transparent or translucent, low viscous mixture indicates the monophasic nature of the system. $^{14}$

Monophasic mixtures were prepared with different ratios of oil, surfactant, co-surfactant and water. To construct pseudoternary phase diagram (CHEMIX $^{\circledR}$ School software) these monophasic mixtures were plotted on three diagonals of the triangle. Resulted triangle's shaded area represents monophasic emulsion and considered as the area of a stable microemulsion. All titrations were repeated thrice to get reproducible results. Extract loaded microemulsion prepared by solubilizing extract in the oil and further following the same procedure.

\section{Evaluation of Microemulsion System Thermodynamic stability studies}

TPE subjected for thermodynamic stability with the help of stress tests applied in series. In this test, TPE microemulsion was checked for thermodynamic stability upon centrifugation at $3000 \mathrm{rpm}$ for $30 \mathrm{~min}$. Stable formulations that did not cream, crack or separate into two layers, were further subjected for the next test. The stability of the formulations at varied temperatures was tested by storing them at $45^{\circ}$ and $4^{\circ}$ each for a period of $48 \mathrm{hr}$. The samples were exposed to heating and cooling cycles which was repeated six times for each sample. Formulations which were stable with reference to their physical integrity at these temperatures were exposed to freeze-thaw cycle that involved storing formulations between $-21^{\circ}$ and $+25^{\circ}$ each for a minimum period of $48 \mathrm{hr}$. Thermodynamically stable formulations were selected for further optimization. ${ }^{17}$

\section{Physicochemical characterization}

\section{Conductivity measurement}

Electrical conductivity $(\sigma)$ of the TPE microemulsion was studied using conductivity meter. Measurements were done to study the effect of the amount of water on the nature of microemulsion and to determine the type of a system; oil-continuous, bi-continuous or water continuous. ${ }^{18}$

\section{pH}

The $\mathrm{pH}$ of TPE loaded microemulsion was measured using a calibrated $\mathrm{pH}$ meter at $25 \pm 1^{\circ}$. The measurements were performed and recorded in triplicate. ${ }^{15}$

\section{Viscosity}

Viscosity affects the interaction between the different molecules and ultimately effects on the friction in between the molecules present in the fluid. Viscosity measurement of the microemulsion was carried out in triplicates with help of Brookfield viscometer (DV-III+, Programmable Rheometer). ${ }^{7}$

\section{Droplet size, polydispersity index and zeta potential measurement}

The droplet size, polydispersity index and zeta potential of the optimized formulation was measured by dynamic light scattering (DLS) using Malvern Zetasizer (Malvern 2000 Hydro SM) and Zetasizer (Micro ZS).

\section{In vitro diffusion study}

In vitro release studies gives us information about the amount of drug released from the formulation. It was performed using a dialysis bag method with molecular weight cutoff of $12,000 \mathrm{Da}$. Dialysis membrane retains microemulsion and molecules released over the time into sodium citrate buffer as with $\mathrm{pH} 5$ used as dissolution medium. Microemulsion was transferred and tightly tied into the dialysis bag which was placed 
in a vessel containing dissolution medium in dissolution test USP Type II apparatus rotating at $100 \mathrm{rpm}$. Aliquots were withdrawn at time intervals of $1 \mathrm{~h}$ up to $8 \mathrm{~h}$ and analyzed spectrophotometrically using UV visible spectrophotometer (Shimadzu UV-17009) at $254 \mathrm{~nm} .{ }^{19}$

\section{Accelerated stability study}

The accelerated stability study of optimized TPE microemulsion formulation was carried out as per ICH guidelines. Samples of optimized TPE loaded microemulsions were kept in the refrigerator and programmable environmental chamber for three months at $5 \pm 2^{\circ}, 25 \pm 2^{\circ}$ and $60 \pm 5 \%$ relative humidity $(\mathrm{RH})$ and elevated temperature $40^{\circ} \pm 2^{\circ}$ and $75 \pm 5$ RH. Optimized TPE formulations were withdrawn at 1,2 and 3 months storage time from the chamber and evaluated for particle size and zeta potential using Malvern instruments (Malvern 2000 Hydro SM) and Zetasizer (Micro ZS), respectively. ${ }^{14}$

\section{Determination of drug content}

The amount of Tridax procumbens Linn present in the optimized microemulsion was determined by UV spectroscopic method. To a $100 \mathrm{ml}$ volumetric flask 1 $\mathrm{ml}$ microemulsion was transferred followed by addition of a sufficient amount of methanol and the mixture was shaken. The resulting solution was filtered through a $0.45 \mu \mathrm{m}$ Whatman filter paper. Exactly $1 \mathrm{ml}$ of filtrate was transferred to volumetric flask; volume was made to $10 \mathrm{ml}$ by adding methanol and scanned on UV spectrophotometer at $254 \mathrm{~nm}$.

\section{In vivo study}

Dried ethanolic extract of Tridax procumbens Linn. leaves $200 \mathrm{mg} / \mathrm{kg}$ was suspended in $0.5 \%$ sodium carboxy methyl cellulose and used to test its hypoglycemic activity in Wistar rats weighing 200-250 g. Animals were divided into 3 different groups, 6 animals were kept in each group and kept at fasting for $18 \mathrm{hr}$ before the experiment. The first control group was given normal saline followed by the second group was administered with the standard formulation and third group received test formulation. Diabetes was induced by the intravenous administration of alloxan monohydrate, $100 \mathrm{mg} / \mathrm{kg}$. A blood sample, $2 \mathrm{ml}$, was collected after $48 \mathrm{~h}$ from the orbital sinus and instantly used for the estimation of glucose level. Treatment was given to the only those animals whose glycemic levels were found to be either or to above $200 \mathrm{mg} / \mathrm{dl}$. These animals were given a daily administration of prepared microemulsion and extract of leaves of Tridax Procumbens Linn., 200mg/kg for 7 days. All animal groups were treated at the same time in every morning every day under the same situation. The blood was collected one $1 \mathrm{~h}$ after the last administration and blood glucose level was measured. ${ }^{6}$

\section{RESULTS}

\section{Preliminary phytochemical studies \\ Thin layer chromatography}

The ethanolic extract of dried leaves of Tridax procumbens Linn.was subjected to thin layer chromatography for confirmation of the presence of quercetin flavonoid. The dark brownish yellow color spot appeared under iodine chamber. Pure quercetin and TPE showed $\mathrm{R}_{f}$ value 0.7 and 0.6 respectively, Table 1 , indicating presence of flavonoid in extract.

\section{Isolation of active constituent}

Five fractions were collected from column chromatography and were analyzed using TLC and UV spectrophotometry at $254 \mathrm{~nm}$ for confirmation of flavonoids. The $\mathbf{R}_{f}$ values are presented in Table 1 indicate the fraction No. 3 showed 0.66 which is very close to that of pure quercetin which shows $R f$ at 0.7 and thus is an active moiety.

\section{Criteria for the selection of components}

One of the factors that involved in the choice of components in the microemulsion system is the solubility of the TPE. Therefore, it is important that the TPE must have high solubility in all components used in the microemulsion system. The results of the solubility study showed that olive oil has the highest solubility $4.2 \mathrm{mg} / \mathrm{ml}$ among all the other screened oils namely ethyl oleate, oleic acid, iso-propyl myristate used. Tween 80 had more solubility of $17.38 \mathrm{mg} / \mathrm{ml}$ as compare to others to the tween 20, span 80 and span 20 . Propylene glycol 400 had more solubility $4.5 \mathrm{mg} / \mathrm{ml}$ than ethanol and PG. Thus olive oil, tween 80 and propylene glycol 400 were chosen as oil phase, surfactants and co-surfactant, respectively.

\section{Drug excipient compatibility studies}

The FTIR spectrum shows the main functional groups present in the TPE. Drug-excipient compatibility studies were performed to eliminate any compatibility issues of any of the components in the microemulsion system with the TPE. The spectrum in Figure 1 indicates that none of the components interfere with the functional group of the drug.

\section{Pseudo ternary phase diagrams}




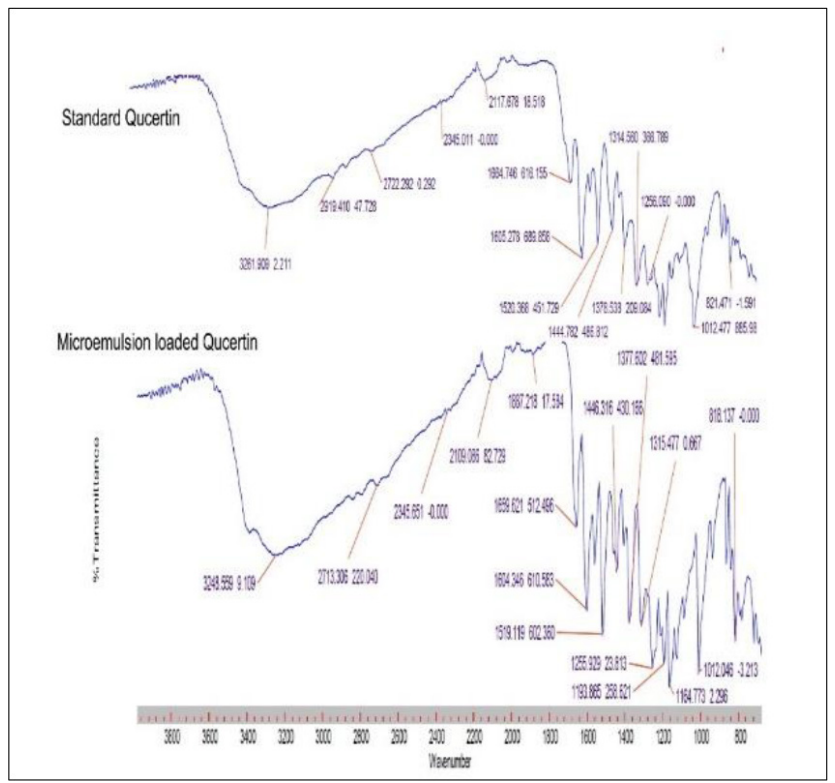

Figure 1: FTIR spectrum of TPL and TPL microemulsion.

The pseudo ternary phase diagrams were constructed by varying the concentrations of surfactant Tween 80 having HLB 15. The propylene glycol 400 having HLB value 11 was used as co-surfactant while olive oil was oil phase and distilled water as the aqueous phase. It is observed at low surfactant and co-surfactant $\left(\mathrm{S}_{\text {mix }}\right)$ concentration the emulsion formed was biphasic and unstable. These emulsions were turbid and milky white. As the $\mathrm{S}_{\text {mix }}$ ratio increases, the clear, translucent to transparent Microemulsions were formed which were stable and there was no phase separation. Another important factor is the concentration of oil in the microemulsion which is required to solubilize the maximum quantity of TPE but, as the oil concentrationincreases the phase separation occur.

The pseudoternary phase diagram in Figure 2 gives relevant information on the optimum ratio of oil, surfactant and co-surfactant that has to be used for preparation of a thermodynamically stable microemulsion. To check the usefulness of the formulated microemulsion as suitable drug delivery system for TPE, the TPE equivalent to one dose is incorporated into the oil phase and similar phase diagrams were constructed. The phase behavior of the TPE loaded system did not change. The monophasic, clear and transparent formulations were further characterized for thermodynamic stability as one of the criteria to optimize the best formulation. The nonionic surfactants and co-surfactant, Tween 80, PEG 400 used in the formulation reduces the interfacial tension between oily phase and aqueous phase resulting in mono phasic microemulsion that remains stable over a period

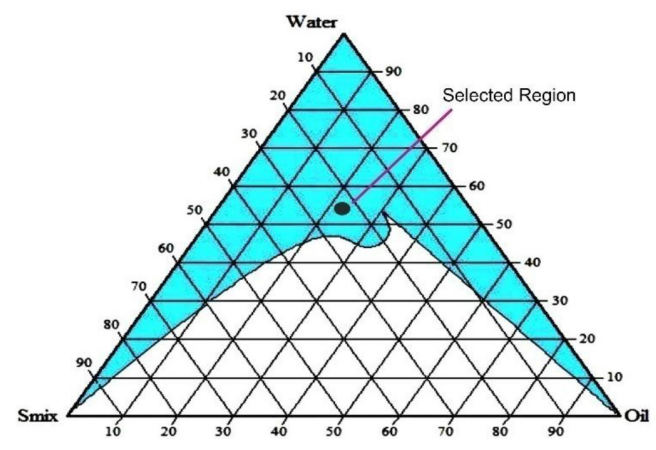

Figure 2: Pseudo ternary phase diagrams.

\begin{tabular}{|c|c|c|}
\hline \multicolumn{3}{|c|}{ Table 2: Effect of pH and viscosity on formulations. } \\
\hline Formulation & $\begin{array}{c}\text { pH } \\
\text { (Standard deviation) }\end{array}$ & $\begin{array}{c}\text { Viscosity } \\
\text { (Standard deviation) }\end{array}$ \\
\hline Q1 & $5.15 \pm 0.04713$ & $65.33 \pm 0.1632$ \\
\hline Q2 & $5.45 \pm 0.04714$ & $64.26 \pm 0.0942$ \\
\hline Q3 & $4.85 \pm 0.04714$ & $63.86 \pm 0.0471$ \\
\hline
\end{tabular}

of time. Tween 80 is the commonly added pharmaceutical excipient that is considered non-toxic and inert, used to increase aqueous solubility. ${ }^{19}$

\section{Appearance and clarity}

The formulations were exposed to stress studies such as centrifugation and heating-cooling effect using freezethaw cycle. All formulations passed the visual tests as they appeared clear and transparent.

\section{Conductivity measurements}

The electrical conductivity has been traditionally used to test the type of emulsion as one among oil continuous, bicontinuous or water continuous. It was based upon percolation theory where conductivity was seen rapidly increasing with the increase in the amount of water. A slight decrease in conductivity was observed on further dilution with water. These observations clearly point that the microemulsion prepared is water continuous type or oil in water type.

\section{pH}

The $\mathrm{pH}$ of the optimized formulation (Q2) was $5.45 \pm 0.04714$ which is best for oral administration. The values presented in Table 2 indicates that incorporation of TPE did not significantly affect the $\mathrm{pH}$ of the prepared microemulsion.

\section{Viscosity}

The optimized formulation Q2 viscosity was $64.26 \pm$ $0.0942 \mathrm{cP}$ with the increase in the concentration of Tween 80 and the co-surfactant PEG 400, viscosity also increased. Viscosity of microemulsion decreases 
with a decrease in oil concentration and increase in water concentration.

\section{Droplet size measurement}

The measurement of particle size of microemulsion globules are important to ensure that emulsion was micro droplets. Figure 3 reflects microemulsion formed having droplets size $292.4 \mathrm{~nm}$ with 0.252 polydispersity index which is optimized formulation (Q2).

\section{Zeta potential of microemulsion}

Zeta potential shows the stability of microemulsion, the optimized Q2 formulation shows -21.6 Mv, Figure 4. Aggregation is not expected to happen, due to the slightly negative charge of the droplets. The values of particle size presented in Table 3 indicate that droplet size is small enough and hence has high zeta potential confirming the stability of microemulsion. ${ }^{12-14}$ It indicates that droplets were stable with no aggregation and

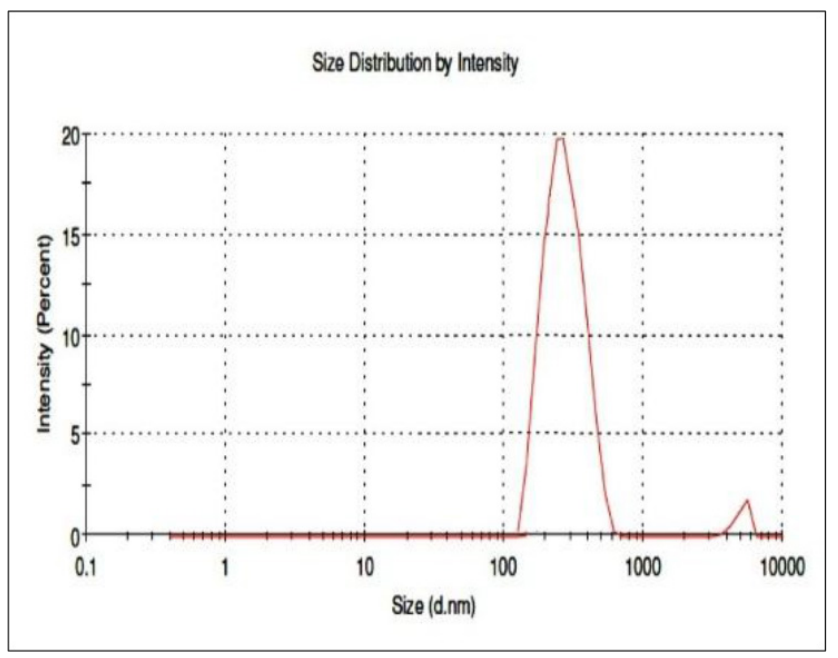

Figure 3: Droplet size measurement of batch Q2.

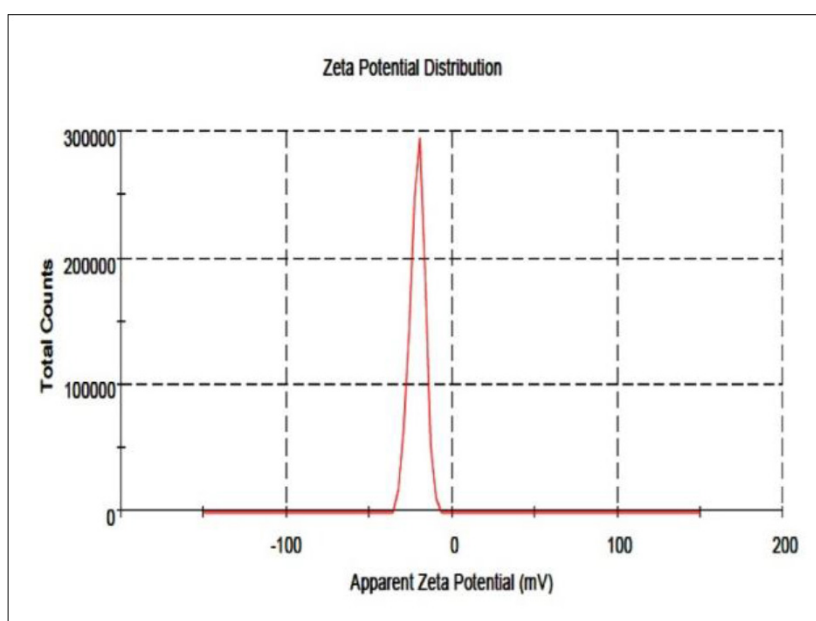

Figure 4: Zeta potential of optimized batch Q2.

\begin{tabular}{|c|c|c|c|c|}
\hline Formulation & $\begin{array}{c}\text { Particle } \\
\text { Size (d. } \mathbf{n m})\end{array}$ & PDI & $\begin{array}{c}\text { Zeta } \\
\text { Potential } \\
(\mathrm{mV})\end{array}$ & $\begin{array}{c}\text { Drug } \\
\text { content } \\
(\%)\end{array}$ \\
\hline Q1 & 372.7 & 0.246 & -13.6 & 97.10 \\
\hline Q2 & 431.1 & 0.292 & -21.6 & 98.04 \\
\hline Q3 & 292.4 & 0.254 & -34.5 & 97.30 \\
\hline
\end{tabular}

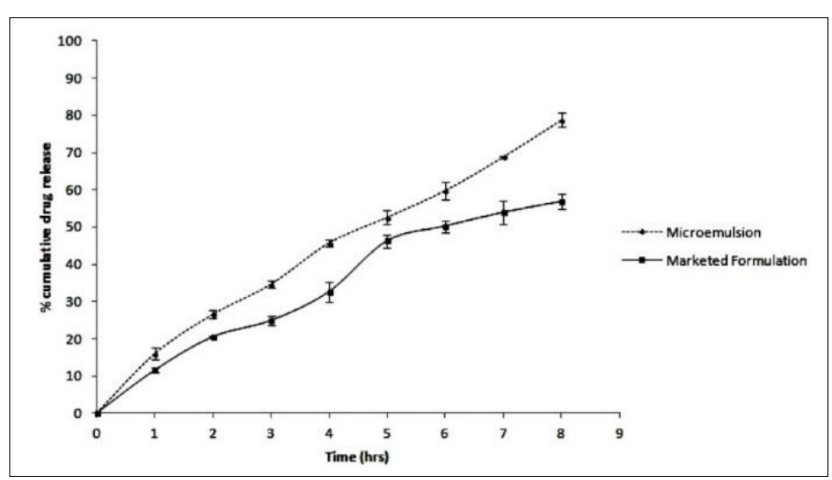

Figure 5: In vitro drug release studies of optimized batch Q2 and marketed formulation.

fluctuation in the microemulsion. All batches were having sufficient charge and mobility to inhibit aggregation of particles.

\section{In vitro release studies}

Release and diffusion of the drug from the microemulsion were calculated using the data of percentage drug diffused in the given time into the equations of zero order, first order, Higuchi and Korsmeyer pappas model. The in vitro drug release studies, Figure 5, shows that the drug release from optimized formulation follows Higuchi matrix model. This was concluded by a higher regression coefficient value in the curve fitting. Drug released from the optimized Q2 formulation and marketed tablet formulation was found to be as $80.26 \%$ and 59.93\%, respectively. Surfactants and co-surfactants solubilize the oil by forming micelles thereby reducing the interfacial tension between oil and water. Thus when TPE is dissolved in oil its solubility improved. Microemulsion showed higher drug release as compared to the marketed formulation which may be attributed to the solubility enhancing component of the surfactant and co-surfactant.

\section{Accelerated stability study}

The results of the accelerated stability studies show that the microemulsion did not change significantly in the physical appearance, assay and droplet size. Microemulsion when observed under the microscope 


\begin{tabular}{|c|c|c|c|c|c|}
\hline \multicolumn{2}{|c|}{ Group } & I & II & III & IV \\
\hline \multicolumn{2}{|c|}{ Treatment } & Control & Test (extract) & Test (formulation) & Standard \\
\hline \multicolumn{2}{|c|}{ Normal Blood Glucose (mg/dl) } & $\begin{array}{l}75 \\
82 \\
85\end{array}$ & $\begin{array}{l}78 \\
79 \\
84\end{array}$ & $\begin{array}{l}80 \\
78 \\
69\end{array}$ & $\begin{array}{l}84 \\
79 \\
82\end{array}$ \\
\hline \multicolumn{2}{|c|}{ Diabetic Blood Glucose (mg/dl) } & - & $\begin{array}{l}287 \\
290 \\
310\end{array}$ & $\begin{array}{l}280 \\
285 \\
290\end{array}$ & $\begin{array}{l}316 \\
325 \\
298\end{array}$ \\
\hline \multirow{7}{*}{$\begin{array}{l}\text { Blood glucose } \\
\text { level (mg/dL) }\end{array}$} & Day 1 & $\begin{array}{l}76 \\
79 \\
80\end{array}$ & $\begin{array}{l}272 \\
265 \\
300\end{array}$ & $\begin{array}{l}270 \\
263 \\
244\end{array}$ & $\begin{array}{l}270 \\
309 \\
245\end{array}$ \\
\hline & Day 2 & $\begin{array}{l}75 \\
72 \\
82\end{array}$ & $\begin{array}{l}251 \\
238 \\
278\end{array}$ & $\begin{array}{l}269 \\
256 \\
242\end{array}$ & $\begin{array}{l}215 \\
295 \\
222\end{array}$ \\
\hline & Day 3 & $\begin{array}{l}74 \\
73 \\
77\end{array}$ & $\begin{array}{l}203 \\
206 \\
246\end{array}$ & $\begin{array}{l}201 \\
200 \\
182\end{array}$ & $\begin{array}{l}198 \\
276 \\
249\end{array}$ \\
\hline & Day 4 & $\begin{array}{l}75 \\
75 \\
80\end{array}$ & $\begin{array}{l}138 \\
200 \\
219\end{array}$ & $\begin{array}{l}196 \\
198 \\
169\end{array}$ & $\begin{array}{l}190 \\
253 \\
216\end{array}$ \\
\hline & Day 5 & $\begin{array}{l}76 \\
74 \\
75\end{array}$ & $\begin{array}{l}131 \\
190 \\
195\end{array}$ & $\begin{array}{l}174 \\
168 \\
148\end{array}$ & $\begin{array}{l}180 \\
234 \\
186\end{array}$ \\
\hline & Day 6 & $\begin{array}{l}71 \\
74 \\
83\end{array}$ & $\begin{array}{l}119 \\
145 \\
150\end{array}$ & $\begin{array}{l}132 \\
156 \\
125\end{array}$ & $\begin{array}{l}130 \\
184 \\
146\end{array}$ \\
\hline & Day 7 & $\begin{array}{l}74 \\
73 \\
68\end{array}$ & $\begin{array}{l}102 \\
103 \\
123\end{array}$ & $\begin{array}{c}101 \\
95 \\
93\end{array}$ & $\begin{array}{l}109 \\
135 \\
138\end{array}$ \\
\hline
\end{tabular}

there was no droplet aggregation, whereas at the same time the droplets were of uniform size. This indicates the stability of prepared microemulsion.

\section{Determination of drug content}

The amount of drug present in the stable microemulsion formulation Q2 was found to be $98.4 \%$.

\section{In vivo experimental study}

The results of in vivo experimental studies presented in Table 4 reveals that the ethanolic extracts of Tridax procumbens Linn. leaves $(200 \mathrm{mg} / \mathrm{kg}$ ) orally administered for 7 days produced a significant decrease in the blood glucose level in the model of alloxaninduced diabetes in rats. The active constituent quercetin has poor bioavailability hence its microemulsion was prepared. The effective surface area of this drug would directly influence its solubility and the dissolution rate. This increased surface area has direct impact on the improved contact with the intestinal mucosa and thus better absorption. Thus microemulsion showed improvement in aqueous solubility and the bioavailability of drug that significantly reduced blood glucose level.

\section{CONCLUSION}

The effect of oral administration of ethanolic extracts of Tridax procumbens leaves $(200 \mathrm{mg} / \mathrm{kg}$ ) for 7 days produce significant decrease in the blood glucose level in the model of alloxan-induced diabetes in rats. The efficient formation of extract loaded microemulsion with droplet size in the micrometer range has facilitated the incorporation of poorly water soluble extract into the oil in water emulsion system. Effective solubilization was accomplished using the microemulsification method. It is evident that this novel formulation improves in vitro diffusion and systemic exposure that evidently points towards its better therapeutic efficacy to be used as oral drug therapy.

\section{ACKNOWLEDGEMENT}

Authors would like to acknowledge Dr. H. N. More, Principal, Bharati Vidyapeeth College of Pharmacy, Kolhapur for support and valuable suggestions during this research studies. 


\section{CONFLICT OF INTEREST}

The authors declare that there is no conflict of interests regarding the publication of this paper.

\section{ABBREVIATIONS}

UV: Ultra visible; TPE: Tridax procumbens Linn; TLC: Thin Layer Chromatography; $\mathbf{R}_{\boldsymbol{f}}$ Retention Factor; RH: Relative humidity; HLB: Hydrophilic lipophilic balance; $\mathbf{S}_{\text {mix }}$ : Surfactant; Co-surfactant mixture; PEG: Polyethylene glycol; FTIR: Fourier transfer infrared.

\section{REFERENCES}

1. idf.org International Diabetes Federation, Diabetes Atlas. 2017. Eighth edition Available from: https://diabetesatlas.org/

2. Li R, Zhang P, Barker LE, Chowdhury FM, Zhang X. Cost-effectiveness of interventions to prevent and control diabetes mellitus: A systematic review. Diabetes Care. 2010;33(8):1872-94.

3. Bhalerao SA, Kelkar TS. Phytochemical and pharmacological potential of Tridax procumbens Linn. Int J Adv Bio Res. 2012;2(3):392-95.

4. Sonawane A, Srivastava RS, Sanghavi N, Malode Y, Chavan B. Anti-diabetic activity of Tridax procumbens L. J of Sci and Innov Res. 2014;2:221-6.

5. Ali M, Ravinder E, Ramachandran R. A new flavonoid from the aerial parts of Tridax procumbens. Fitoterapia. 2001;72(3):313-5.

6. Bhagwat DA, Killedar SG, Adnaik RS. Anti-diabetic activity of leaf extract of Tridax procumbens Linn. Int J of Green Pharm. 2008;2(2):126-8.
7. Talegaonkar S, Azeem AAFJ, Khar PK, Pathan SA, Khan ZL, et al. Microemulsions: A novel approach to enhance drug delivery. Recent Pat Drug Deliv Formul. 2008;2(3):238-57

8. Khaled KA, El-Sayed YM, Al-Hadiya BM. Disposition of the flavonoid quercetin in rats after single intravenous and oral doses. Drug Dev Ind Pharm. 2003;29(4):397-403.

9. Mishra A, Panola R, Rana AC. Microemulsions: As drug delivery system. J of Sci and Innov Res. 2014;3(4):467-74.

10. Sharma B, Kumar P. Extracts of Tridax procumbens and Capparis decidua. Int J Appl Res in Nat Prod. 2008;3(1):5-12.

11. Petchi RR, Vijaya C, Parasuraman S. Antidiabetic activity of polyherbal formulation in streptozotocin - nicotinamide induced diabetic wistar rats. J Tradit Complement Med. 2014;4(2):108-17.

12. Pareek H, Sharma S, Khajja BS, Jain K, Jain GC. Evaluation of hypoglycemic and anti-hyperglycemic potential of Tridax procumbens (Linn). Int $\mathrm{J}$ Complement Altern Med. 2009;9(1):48.

13. Kokate CK. A text book of Practical Pharmacognosy, $5^{\text {th }}$ edition, VallabhPrakashan. 2005;107-11.

14. Doshi GM, Une HD. Quantification of Quercetin and Rutin from Benincasahispida seeds and Carissa congesta roots by high-performance thin layer chromatography and high-performance liquid chromatography. Pharmacognosy Res. 2016;8(1):37-42.

15. Omnia S, Mahmoud MI, Mahmoud M. Microemulsions as antidiabetic drug delivery systems. Int J Pharma Sci Res. 2012;3:4442-56.

16. Silverstein RM, Webster FX, Kiemle DJ, Bryce DL. Spectrometric Identification of Organic Compounds, $8^{\text {th }}$ Edition, Wiley. 2014;71-125.

17. Sharma B, Kumar P. Extracts of Tridax procumbens and Capparis decidua. Int J Appl Res in Nat Prod 2009;1:5-12.

18. Kamath $\mathrm{H}$, Sivakumar $\mathrm{A}$. Microemulsion based formulation as drug delivery system for gliclazide. Int J Pharm Edu Res. 2017;51:571-9.

19. D'Souza S. A review of in vitro drug release test methods for nano-sized dosage forms. Adv in Pharm. 2014;1-12.

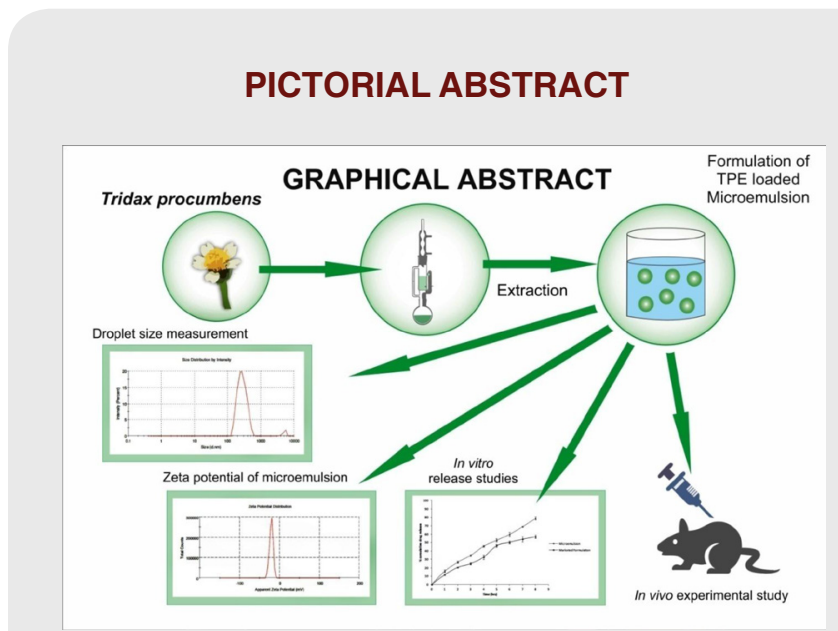

\section{SUMMARY}

The present study was focused to scientifically overcome bioavailability drawbacks of Tridax procumbens Linn. and improve its medicinal use for the treatment of diabetes by formulating it into microemulsion. Water microemulsion of this extract was prepared using olive oil, Tween 80 and propylene glycol for oral delivery to treat diabetes mellitus. The optimized Tridax procumbens Linn. extract microemulsion showed an average particle size $292.4 \mathrm{~nm}$. There was approximately 1.4 fold increase in drug release from microemulsion compared to marketed tablet formulation. At the end of seven days after oral administration of microemulsion a significant reduction in blood glucose level was observed. The optimized microemulsion was thermodynamically stable. The enhanced bioavailability of flavonoids in microemulsion proves the traditionalclaim withregard to Tridax procumbens Linn. for its antidiabetic activity. 


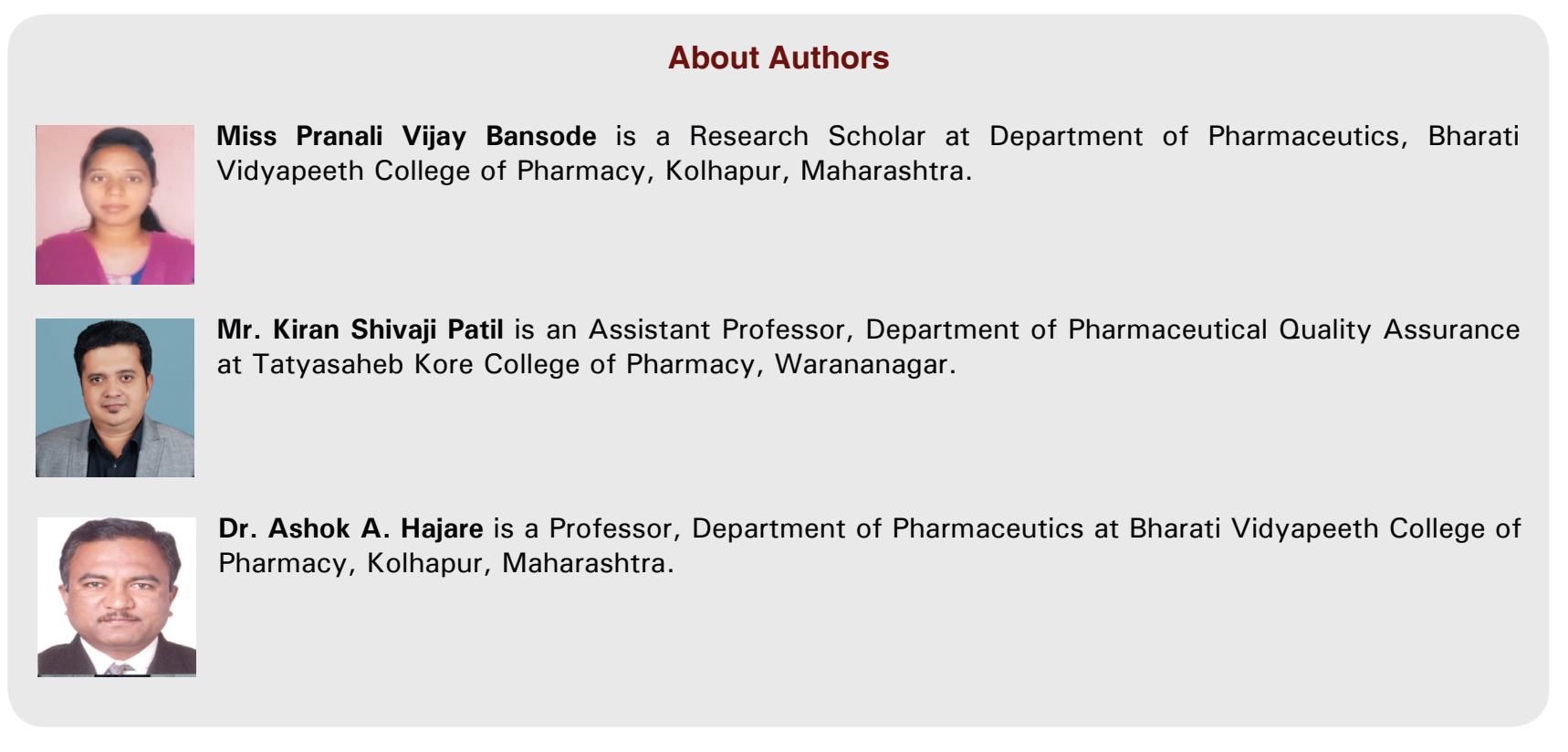

Cite this article: Bansode PV, Patil KS, Hajare AA. Bioactivity Guided Antidiabetic Formulation Development of Tridax procumbens Linn Leaves. Indian J of Pharmaceutical Education and Research. 2020;54(3):705-13. 